\title{
MORTALITY AND FATAL PULMONARY EMBOLISM AFTER PRIMARY TOTAL HIP REPLACEMENT
}

\author{
RESULTS FROM A REGIONAL HIP REGISTER
}

D. FENDER, W. M. HARPER, J. R. THOMPSON, P. J. GREGG

From the University of Leicester, England

We calculated the rates for perioperative mortality and fatal pulmonary embolism (PE) after primary total hip replacement in a single UK health region, using a regional arthroplasty register and the tracing service of the Office of National Statistics. During 1990, there were 2111 consecutive primary replacements in 2090 separate procedures. Within $\mathbf{4 2}$ days of operation a total of 19 patients had died $(0.91 \%, 95 \%$ CI 0.55 to 1.42$)$. Postmortem examination showed that four deaths $(0.19 \%, 95 \%$ CI 0.05 to 0.49$)$ were definitely due to PE.

The overall perioperative mortality and fatal PE rates are low and in our study did not appear to be altered by the use of chemical thromboprophylaxis (perioperative mortality rate: one-tailed Fisher's exact test, $p=0.39$; fatal $P E$ rate: one-tailed Fisher's exact test, $p=0.56$ ).

The routine use of chemical thromboprophylaxis for primary THR is still controversial. The issue should be addressed by an appropriate randomised, prospective study using overall mortality and fatal PE rate as the main outcome measures, but the feasibility of such a study is questioned.

J Bone Joint Surg [Br] 1997;79-B:896-9.

Received 10 February 1997; Accepted after revision 18 July 1997

D. Fender, FRCS, Orthopaedic Research Fellow

W. M. Harper, MD, FRCS Ed, Senior Lecturer and Honorary Consultant Orthopaedic Surgeon

University of Leicester, Clinical Sciences Building, Glenfield General NHS Trust, Groby Road, Leicester LE3 9QP, UK.

P. J. Gregg, MD, FRCS, Professor of Orthopaedic Surgery

The Medical School, Framlington Place, Newcastle upon Tyne NE1 7RU, UK.

J. R. Thompson, PhD, Senior Lecturer in Epidemiology and Public Health Medicine

University of Leicester, Clinical Sciences Building, Leicester Royal Infirmary, Infirmary Square, Leicester LE1 5WW, UK.

Correspondence should be sent to Mr D. Fender at the Department of Orthopaedic Surgery, The Medical School, Framlington Place, Newcastle upon Tyne NE1 7RU, UK.

(C) 1997 British Editorial Society of Bone and Joint Surgery

0301-620X/97/67677\$2.00
Death from pulmonary embolism (PE) is a recognised complication of total hip replacement (THR), but the exact prevalence is unknown. Historical reports suggested a fatal PE rate of $2.3 \%$ to $3.4 \%,{ }^{1,2}$ but more recent series have shown that the overall mortality after THR is only of the order of $1 \% .^{3-5}$ Two recent papers have reported fatal PE rates of $0.34 \%$ and $0.38 \%$. Both were from single centres, one a specialist orthopaedic unit and one a large district general hospital, neither of which used routine chemical thromboprophylaxis. Both series included a proportion of patients who had revision THR and may not therefore be truly representative. A meta-analysis of all studies on THR which included data on death or fatal PE indicated that the rates of both had fallen since the 1960s and that the current death rate was $0.3 \%$ to $0.4 \%$ with a fatal PE rate of $0.1 \%$ to $0.2 \%{ }^{8}$

The main controversy concerns the use of chemical thromboprophylaxis and the prevention of fatal PE. The earlier high rates for fatal PE are sometimes quoted to support the use of chemical thromboprophylaxis; ${ }^{9}$ claims have been made that failure to use such prophylaxis may be deemed negligent. ${ }^{10}$ A Working Party of the Royal College of Surgeons on venous thromboprophylaxis ${ }^{11}$ felt that the issue was unresolved, and that "each patient should have a risk assessment and be managed according to the surgeon's current practice".

Our prospective, observational study assessed the rate of fatal PE in a large cohort of consecutive primary THRs performed in a single UK health region, providing a descriptive analysis of the use of chemical thromboprophylaxis in the cohort.

\section{PATIENTS AND METHODS}

We studied all patients having a primary THR in 1990, as registered with the Trent Regional Arthroplasty Study (TRAS). This is the only regional arthroplasty register in England which, since the beginning of 1990, has recorded prospectively all primary total hip and knee replacements performed throughout the Trent region. Patients are entered at the time of the operation by the surgeon who completes a standard form recording demographic, medical and operative details including the use and type of chemical 
Table I. Comparison of the groups with and without chemical prophylaxis

\begin{tabular}{|c|c|c|c|c|c|c|}
\hline \multirow{2}{*}{$\begin{array}{l}\text { Chemical } \\
\text { prophylaxis }\end{array}$} & \multirow[b]{2}{*}{$\%$ male } & \multicolumn{2}{|c|}{ Age (\%) } & \multicolumn{3}{|c|}{ Primary diagnosis $(\%)$} \\
\hline & & $\leq 60$ & $\geq 61$ & $\overline{\mathbf{O A}}$ & RA & Other \\
\hline Yes $(n=1226)$ & 39.7 & 26 & 74 & 86 & 7 & 7 \\
\hline No $(n=667)$ & 38.8 & 20 & 80 & 88 & 6 & 6 \\
\hline
\end{tabular}

thromboprophylaxis. This is then returned to the study centre and the data are validated by a peripatetic clerk who checks theatre records, consultant records and the patient administration system of each hospital, to ensure that no data are lost.

We began a detailed five-year assessment of the 1990 primary THRs in 1995, attempting to contact all patients. Details of those missing were supplied by a tracing service of the Office of National Statistics and the 1995 status of all the cohort is known. For patients who had died, the date, place, and certified cause of death are known, with details of all postmortem examinations which were performed.

During 1990, there were 2111 consecutive primary THRs in 2036 patients, under the care of 66 consultants, in 19 national health service and seven private hospitals. Twentyone patients had a bilateral procedure and another 54 had both hips replaced during the year under study. A total of 2090 separate primary procedures was performed.

The medical records were scrutinised to validate data supplied to TRAS and to record details of the past medical history, the drug history, the operation and the postoperative period. We analysed data to compare groups of patients and the use of chemical thromboprophylaxis by logistic regression models and adjusted odds ratios using the SPSS version 7.0 for windows (SPSS Inc, Chicago, Illinois). The $95 \%$ confidence intervals (CI) have been given where appropriate, using the formula for the standard error of a proportion based on the normal approximation of the Poisson distribution. ${ }^{12}$

\section{RESULTS}

Chemical thromboprophylaxis. Information on the use or avoidance of chemical thromboprophylaxis was available for 1893 of cases and not known for 218. A comparison of these two groups using independent univariate logistic regression analysis showed no significant differences for age $(\leq 60, \geq 61$ years; $p=0.620)$, gender $(p=0.234)$ or primary diagnosis (osteoarthritis, rheumatoid arthritis, other; $\mathrm{p}=0.71)$.

Of the 1893 arthroplasties for which the use or otherwise of chemical thromboprophylaxis was known, 1226 (64.8\%) received some form of agent and 667 (35.2\%) had none. Comparison of these two groups using independent univariate logistic regression analysis showed no significant differences for gender $(p=0.705)$ or primary diagnosis $(\mathrm{p}=0.335)$. There was a statistically significant difference for the age of the patients $(p=0.002)$ : a greater proportion of the younger patients received chemical thrombo-
Table II. Analysis of the risk factors for thromboembolic disease in the 1873 THRs for which details of chemical thromboprophylaxis (CTP) and a full medical history were available

\begin{tabular}{|c|c|c|c|c|}
\hline \multirow[b]{2}{*}{ Risk factor } & \multirow[b]{2}{*}{ Number } & \multicolumn{2}{|l|}{ CTP use } & \multirow{2}{*}{$\begin{array}{l}p \text { value } \\
\text { of difference }\end{array}$} \\
\hline & & Number & $\%$ & \\
\hline None & 1114 & 698 & 63 & \\
\hline Cardiac disease & 594 & 382 & 64 & 0.935 \\
\hline Varicose veins & 98 & 67 & 68 & 0.405 \\
\hline Malignancy & 101 & 72 & 71 & 0.142 \\
\hline History of DVT/PE & 56 & 53 & 95 & 0.0001 \\
\hline
\end{tabular}

prophylaxis $(71 \% \leq 60$ years $v 62 \% \geq 61$ years) (Table I).

Full medical and thromboprophylaxis data were available for 1873 THRs and this was analysed to assess the effect of certain risk factors (cardiac disease, varicose veins, malignancy and thromboembolic disease), on the chemical thromboprophylaxis as documented in the preoperative notes (Table II). The only one which led to a significantly greater use of chemical thromboprophylaxis was a previous history of thromboembolic disease $(\mathrm{p}=0.0001)$, but this was relatively rare, applying to only 56 cases. Stepwise multivariate logistic regression analysis confirmed that finding $(\mathrm{p}=0.0001)$ and showed that age $(p=0.0012)$ was the only other variable which differed significantly between the groups that did and did not receive chemical thromboprophylaxis. The adjusted odds ratio for a previous history of thromboembolic disease was 3.261 (95\% CI 1.819 to 5.844) and for age 1.21 (95\% CI 1.078 to 1.358 ). When adjusted for other factors including age, a patient with a previous history of thromboembolic disease was over three times more likely to receive chemical thromboprophylaxis.

Mortality and fatal PE rate. Within 42 days of surgery, 19 patients (Table III) had died $(0.91 \%$ of procedures, $95 \% \mathrm{CI}$ 0.55 to 1.42 ). Ten of these had received chemical thromboprophylaxis, seven had received none and for two patients the data were missing. The mortality rate with chemical thromboprophylaxis was $10 / 1226(0.82 \%, 95 \%$ CI 0.39 to $1.50)$ and without it $7 / 667(1.05 \%, 95 \%$ CI 0.42 to 2.16$)$. There was no significant difference between these mortality rates (one-tailed Fisher's exact test, $\mathrm{p}=0.39$ ).

Four deaths due to PE were confirmed on postmortem examination (Table IV). Two of these were during the inpatient stay, one was at home and one followed admission to another hospital. Three of these patients had received chemical thromboprophylaxis (two subcutaneous heparin and one aspirin). Only one had a significant medical history with atrial fibrillation and anaemia, treated with digoxin and diuretics; this patient became dehydrated soon after the 
Table III. Details of deaths within 42 days of total hip replacement

\begin{tabular}{|c|c|c|c|c|c|}
\hline $\begin{array}{l}\text { Day of } \\
\text { death }\end{array}$ & $\begin{array}{l}\text { Age } \\
(\mathbf{y r})\end{array}$ & Gender & CTP* & Cause of death & Postmortem \\
\hline 0 & 57 & $\mathrm{~F}$ & Yes & Malignant hyperpyrexia & Yes \\
\hline 2 & 86 & $\mathrm{~F}$ & Not stated & Coronary insufficiency & Yes \\
\hline 4 & 74 & M & Yes & Pulmonary oedema & No $\dagger$ \\
\hline 4 & 87 & $\mathrm{~F}$ & No & Haemopericardium & Yes \\
\hline 4 & 83 & $\mathrm{~F}$ & Yes & Pulmonary oedema & Yes \\
\hline 5 & 85 & $\mathrm{~F}$ & Yes & Myocardial infarction & No $\dagger$ \\
\hline 5 & 87 & $\mathrm{~F}$ & No & Cardiogenic shock & No $\dagger$ \\
\hline 5 & 66 & M & No & Pulmonary embolism & Yes \\
\hline 8 & 84 & M & Yes & Congestive cardiac failure & Yes \\
\hline 13 & 77 & $\mathrm{~F}$ & No & Myocardial infarct & No $\dagger$ \\
\hline 14 & 78 & $\mathrm{~F}$ & Yes & Pulmonary embolism & Yes \\
\hline 16 & 71 & $\mathrm{~F}$ & Yes & Pulmonary embolism & Yes \\
\hline 16 & 73 & M & No & Left ventricular failure & No $\dagger$ \\
\hline 17 & 36 & M & Yes & Pulmonary embolism & Yes \\
\hline 18 & 80 & M & Yes & Cardiorespiratory failure & Yes \\
\hline 25 & 72 & M & No & Left ventricular failure & Yes \\
\hline 25 & 80 & M & No & Bronchopneumonia & Yes \\
\hline 25 & 79 & $\mathrm{~F}$ & Not stated & Myocardial infarction & No $\dagger$ \\
\hline 38 & 103 & $\mathrm{~F}$ & Yes & Impacted gallstone in $\mathrm{CBD} \neq$ & Yes \\
\hline
\end{tabular}

Table IV. Details of the four patients proven to have had fatal PE

\begin{tabular}{llllllll}
\hline Case & $\begin{array}{l}\text { Day of } \\
\text { death }\end{array}$ & $\begin{array}{l}\text { Age } \\
(\mathbf{y r})\end{array}$ & Gender & $\begin{array}{l}\text { Past medical } \\
\text { history }\end{array}$ & $\begin{array}{l}\text { Drug } \\
\text { history }\end{array}$ & Complications & CTP* \\
\hline 1 & 5 & 66 & M & Nil & Nil & Nil & Nil \\
2 & 14 & 78 & F & $\begin{array}{l}\text { Atrial fibrillation } \\
\text { Anaemia }\end{array}$ & $\begin{array}{l}\text { Digoxin } \\
\text { Diuretics }\end{array}$ & $\begin{array}{l}\text { Dehydrated 1st day } \\
\text { after operation }\end{array}$ & $\begin{array}{l}\text { Subcut } \\
\text { heparin }\end{array}$ \\
3 & 16 & 71 & F & Nil & Nil & Nil & Aspirin \\
4 & 17 & 36 & M & Nil & Nil & Cerebral infarct 9th & $\begin{array}{l}\text { Subcut } \\
\text { day after operation }\end{array}$ \\
\hline
\end{tabular}

* chemical thromboprophylaxis

operation. One 36-year-old man sustained a cerebral infarction on the ninth postoperative day, was transferred to another hospital and subsequently died from PE. The overall proven fatal PE rate was therefore 4/2090 (0.19\%, 95\% CI 0.05 to 0.49 ). With chemical thromboprophylaxis the rate was $3 / 1226(0.24 \%, 95 \%$ CI 0.05 to 0.71$)$ and when not given $1 / 667(0.15 \%, 95 \%$ CI 0.00 to 0.84$)$. There was no significant difference between these mortality rates (one-tailed Fisher's exact test, $\mathrm{p}=0.56$ ).

Of the 19 patients who died within 42 days, nine had other causes of death proven at postmortem (Table III). Six patients did not have postmortem examinations and it is possible that these deaths were due to PE (Table I). If all six were due to $\mathrm{PE}$ the fatal $\mathrm{PE}$ rate would have been $10 / 2090(0.48 \%, 95 \%$ CI 0.23 to 0.88$)$.

To ensure that no late fatal PEs had been overlooked we scrutinised all deaths up to six months after operation: no additional cases of PE were recorded.

\section{DISCUSSION}

Our results, from a large number of primary THRs at a number of hospitals by many different surgeons, confirm recent published data which have shown the overall perio- perative mortality to be of the order of $1 \%,{ }^{4}$ but are higher than the $0.3 \%$ to $0.4 \%$ derived from meta-analysis. ${ }^{8}$

The rate of proven fatal PE of $0.19 \%$ (95\% CI 0.05 to 0.49 ) is similar to the $0.34 \%$ (95\% CI 0.09 to 0.88 ) reported by Warwick et al ${ }^{6}$ and the $0.38 \%$ reported by Mcgrath et $\mathrm{al}^{7}$ and matches the $0.1 \%$ to $0.2 \%$ calculated by meta-analysis. ${ }^{8}$ The true fatal PE rate in this cohort may be as high as $0.48 \%$ (95\% CI 0.23 to 0.88 ); this emphasises the need for postmortem examination after perioperative deaths.

The two fatal PE rates reported by Warwick et $\mathrm{al}^{6}$ and Mcgrath et $\mathrm{al}^{7}$ were for patients who had received no routine chemical thromboprophylaxis, although in both series particularly high-risk patients had received some form of prophylaxis. Our series suggests that the use of chemical thromboprophylaxis had little effect on either overall mortality or the rate of fatal PE. We recognise that treatment was not randomised, but the groups of patients which did or did not receive chemical prophylaxis were similar, with similar risk factors, except for the few who had a previous history of thromboembolic disease. We found that younger patients were more likely to receive chemical prophylaxis, which was unexpected as these patients are generally fitter and more active. The use of chemical thromboprophylaxis for those with a previous 
history is supported by a survey of members of the British Orthopaedic Association: ${ }^{13} 75 \%$ of them regarded such a history as the most important risk factor.

Orthopaedic surgeons have differing opinions on the need for chemical prophylaxis for routine hip replacements, ${ }^{13,14}$ but recently published rates for fatal PE are a magnitude lower than those often quoted. This suggests that contrary to certain opinions, ${ }^{10}$ it is not negligent to withhold such agents. This view was agreed by $36 \%$ of a sample of members of the British Orthopaedic Association; they considered that low-dose anticoagulants were not a medicolegal necessity in routine THR. ${ }^{15}$

We appreciate the considerable limitations of our data, but feel that they provide an accurate observation of a large mixed cohort of primary THRs in a modern setting. The low overall mortality and rate for fatal PE are encouraging. The improvement which may be gained with the

\section{REFERENCES}

1. Coventry MB, Nolan DR, Beckenbaugh RD. "Delayed" prophylactic anticoagulation: a study of results and complications in 2012 total hip arthroplasties. J Bone Joint Surg [Am] 1973;55-A:1487-92.

2. Johnson R, Green JR, Charnley J. Pulmonary embolism and its prophylaxis following the Charnley total hip replacement. Clin Orthop 1977; 127:123-32.

3. Sheppeard H, Henson J, Ward DJ, O'Connor BT. A clinicopathological study of fatal pulmonary embolism in a specialist orthopaedic hospital. Arch Orthop Trauma Surg 1981;99:65-71.

4. Seagroatt V, Tan HS, Goldacre M, et al. Elective total hip replacement: incidence, emergency readmission rate and postoperative mortality. Br Med J 1991;303:1431-5.

5. Dunsmuir RA, Allan DB, Davidson LA. Early postoperative mortality following primary total hip replacement. J R Coll Surg Edinb 1996; 41:185-7.

6. Warwick D, Williams MH, Bannister GC. Death and thromboembolic disease after total hip replacement: a series of 1162 cases with no routine chemical prophylaxis. J Bone Joint Surg [Br] 1995;77-B: 6-10.

7. Mcgrath D, Dennyson WG, Rolland M. Death rate from pulmonary embolism following joint replacement surgery. J R Coll Surg Edinb 1996;41:265-6 routine use of chemical thromboprophylaxis can only be addressed by an appropriately designed randomised study, ${ }^{6,16}$ but the rare nature of the events means that the size of such trials may make them unfeasible. Based on our data, a relative risk reduction of $25 \%$ in the 42 -day mortality of $1 \%$ may be expected with chemical thromboprophylaxis. A randomised controlled trial with an $80 \%$ power to demonstrate such a difference as statistically significant at the 5\% level would require over 45000 patients. If fatal PE were to be used as the endpoint, over 67000 patients would be required.

We thank the orthopaedic surgeons throughout the Trent region who have supported the Trent Regional Arthroplasty Study and the Office of National Statistics for the tracing study.

The Department of Health has funded the five-year review of the 1990 cohort of primary THRs performed in Trent.

No benefits in any form have been received or will be received from a commercial party related directly or indirectly to the subject of this article.

8. Murray DW, Britton AR, Bulstrode CJK. Thromboprophylaxis and death after total hip replacement. J Bone Joint Surg [Br] 1997;78-B 863-70.

9. THRIFT. Thromboembolic Risk Factors Consensus Group. Risk of and prophylaxis for venous thromboembolism in hospital patients. $\mathrm{Br}$ Med J 1992;305:567-74.

10. Parker-Williams J, Vickers R. Major orthopaedic surgery on the leg and thromboembolism. BMJ 1991;303:531-2.

11. The Venous Thromboembolism Guidelines Working Party. State ment on prophylaxis against venous thromboembolism. Royal College of Surgeons of England, 1995.

12. Breslow NE, Day NE. Statistical methods in cancer research. Vol. 2 The design and analysis of cohort studies. Oxford: University Press, 1987:68.

13. Laverick MD, Croal SA, Mollan RAB. Orthopaedic surgeons and thromboprophylaxis. Br Med J 1991;303:549-50.

14. Owen TD, Coorsh J. The use of thromboprophylaxis in total hip replacement surgery: are the attitudes of orthopaedic surgeons changing? J R Soc Med 1992;85:679-81.

15. Unwin AJ, Jones JR, Harries WJ. Current UK opinion on thromboprophylaxis in orthopaedic surgery: its use in routine total hip and knee arthroplasty. Ann R Coll Surg Engl 1995;77:351-4.

16. Murray DW, Carr AJ, Bulstrode CJK. Pharmacological prophylaxis and total hip replacement. J Bone Joint Surg [Br] 1995;77-B:3-5. 